\title{
CASE OF POISONING
}

\author{
BY \\ 0 I L $0 \mathrm{~F} \quad \mathrm{~W} 0 \mathrm{R}$ M W 0 ( ) D
}

(ARTEMISIA ABSINTHIUM).

BY

WILLIAM SMITH,

OURGEO TO THE CHESTERTIELD AND NORTH DERBYSHIRE HOSPITAL AND DISPENSARY.

Received Aug. 27th.-Read Nov. 25th, 1862.

I AM not aware that any case has been recorded of poisoning by the above substance, and I have therefore considered it desirable to place the following brief account before our Society. From the symptoms, it is evident that the poison may be classed amongst the narcotico-irritants, causing stupor and insensibility, and at the same time producing local irritation of the mucous membrane of the stomach. No allusion is made to it in Taylor "On Poisons." Dr. Thomson, in the 'London Dispensatory' says it (the artemisia absinthium) possesses a narcotic influence, produced by the essential oil, and that when it is desirable to free the remedy from that property it should be given in decoction, as the boiling would dissipate the essential oil on which it depends. Lastly, in Pereira's 'Materia Medica, p. 1351, vol. ii, is the following notice of its supposed poisonous effects: "Borrich says the milk rendered bitter by it proves uoxious to the infant. Large doses irritate the stomach and excite the vascular system. A specific influence over the nervous system, characterised by headache, giddiness, \&c., has been ascribed to it. This has been usually 
supposed to depend on the volatile oil, but a similar power has been assigned to the bitter principle." How much of the effects in the following case may be traced to the general results of a large dose of an essential oil, I have no data to determine; but $I$ believe that the narcotic symptoms must, under any circumstances, be ascribed to a specific injurious agent.

A druggist's shopman in this town was found early one morning by his master, lying on the floor of the shop, perfectly insensible, convulsed, and foaming at the mouth. As the man had never suffered from fits, and the symptoms were of an alarming character, I was at once sent for. I found him no longer violently convulsed; but insensible, the jaws clenched, and the pupils dilated. The pulse was weak, slow, and compressible. From time to time he uttered incoherent expressions, and attempted to vomit. With some difficulty I administered to him repeated doses of stimulants, sal volatile and water, lime water, and an emetic of mustard and sulphate of zinc. The nature of the poison had been already made manifest to me.

Free vomiting ensued, and consciousness partially returned. Artificial warmth was applied to the extremities, and a little brandy and water given at intervals, with draughts of milk and lime water. He gradually recovered. The matters vomited smelt strongly of oil of wormwood, and the nature of the poison was placed beyond doubt by the discovery of the bottle, with marks on its mouth of the oil having been recently poured out. The druggist stated that at least half an ounce had been taken. From the persistent smell of the Ol. Absinthii in the ejected matters, after repeated vomiting, I think this was even less than the real quantity.

The man, on recovering had totally forgotten all circumstances connected with the case, and persisted in stating that he knew no reason why he should have taken it. It is, however, probable that he imagined himself suffering from ascarides, and sought relief in a good dose of this vegetable anthelmintic. 